\title{
Stability Study of Darunavir Ethanolate Tablets Applying a New Stability-Indicating HPLC Method
}

\author{
Josilene Chaves Ruela Corrêa, ${ }^{1}$ Cristina Helena dos Reis Serra, \\ and Hérida Regina Nunes Salgado ${ }^{1}$ \\ ${ }^{1}$ Drugs and Pharmaceuticals Quality Control Laboratory, School of Pharmaceutical Sciences, University Estadual Paulista, \\ Rodovia Araraquara-Jaú, km 1, 14801-902 Araraquara, SP, Brazil \\ ${ }^{2}$ School of Pharmaceutical Sciences, University of São Paulo, Av. Professor Lineu Prestes, 580, 05508-000 São Paulo, SP, Brazil \\ Correspondence should be addressed to Josilene Chaves Ruela Corrêa; josilenechavescorrea@gmail.com
}

Received 30 January 2013; Revised 1 April 2013; Accepted 9 April 2013

Academic Editor: Osama Y. Aldirbashi

Copyright (C) 2013 Josilene Chaves Ruela Corrêa et al. This is an open access article distributed under the Creative Commons Attribution License, which permits unrestricted use, distribution, and reproduction in any medium, provided the original work is properly cited.

\begin{abstract}
Chemical and physical degradation of drugs may result in altered therapeutic efficacy and even toxic effects. Therefore, the aim of this work was to study the stability of darunavir and to develop and validate a liquid chromatography (LC) method to determine darunavir in raw material and tablets in the presence of degradation products. The novel method showed to be linear from 6.0 to $21.0 \mu \mathrm{g} / \mathrm{mL}$, with high precision $(\mathrm{CV}<2 \%$ ) and accuracy (recuperation of 99.64\%). It is simple and reliable, free of placebo interferences. The robustness of the method was evaluated by a factorial design using seven different parameters. Forced degradation study was done under alkaline, acidic, and oxidative stress at ambient temperature and by heating. The LC method was able to quantify and separate darunavir and its degradation products. Darunavir showed to be unstable under alkaline, acid, and oxidative conditions. The novelty of this study is understanding the factors that affect darunavir ethanolate stability in tablets, which is the first step to unravel the path to know the degradation products. The novel stability-indicating method can be used to monitor the drug and the main degradation products in low concentrations in which there is linearity.
\end{abstract}

\section{Introduction}

According to the World Health Organization (WHO) AIDS epidemic updates, in 2009 new HIV infections were reduced by $17 \%$ over the previous eight years. Data from WHO also show that there are more people living with HIV than ever before as people are living longer due to the beneficial effects of antiretroviral therapy along with population growth [1] WHO estimates that since the availability of effective treatment in 1996, some 2.9 million lives have been saved [1]. In accordance with Sharma and Garg, the current clinical therapeutic practice of using Highly Active Antiretroviral Therapy (HAART), is considered as one of the most significant advances in the field of HIV therapy [2].

As an important component of the HAART, darunavir (Figure 1), a synthetic nonpeptidic protease inhibitor developed by the pharmaceutical company Tibotec in 1998 [3], has demonstrated high efficacy against $\operatorname{HIV}[4,5]$. This compound was licensed in June 2006 in the United States and in February 2007 in the European Union [1]. The daily dose of darunavir (600 $\mathrm{mg}$ twice a day) has to be administered along with low dose $(100 \mathrm{mg})$ of ritonavir as a booster and food [6] which contributes to better solubilization of the drug in the lumen [6].

Darunavir is marketed in ethanolate form under the brand name of Prezista, and it is available in different dose strengths such as $75,150,300,400$, and $600 \mathrm{mg}$. In addition, Prezista is available as an oral suspension in which the darunavir dose is $100 \mathrm{mg} / \mathrm{mL}$. The dosage form used in this study was Prezista $300 \mathrm{mg}$ darunavir tablets. This dosage has the following composition: $325.24 \mathrm{mg}$ of darunavir ethanolate and the inactive ingredients (crospovidone, magnesium stearate, Opadry II White (partially hydrolyzed polyvinyl alcohol, titanium dioxide, macrogol, and talc), and Prosolv (microcrystalline cellulose and colloidal silicon dioxide)). 


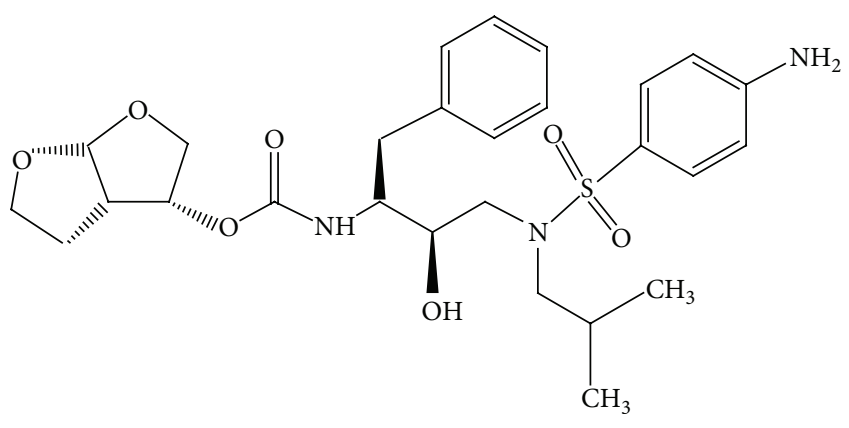

Figure 1: Chemical structure of darunavir.

As HIV is a global disease, darunavir is used throughout the world and thus stored under different environmental conditions. Because of this, it is extremely important to study the stability of darunavir keeping in mind that pharmaceuticals are especially sensitive to environmental factors.

Stability can be defined as the capacity of a drug substance or product to remain within established specifications and to maintain its identity, strength, quality, and purity throughout expiration dating period [7]. Stability test of an active pharmaceutical ingredient or drug product can provide evidence on the drug quality and if it can be influenced by a variety of environmental factors such as temperature and humidity [7]. Chemical and physical degradation of drugs may result in altered therapeutic efficacy and even toxic effects. Therefore, understanding the factors that change the stability of pharmaceuticals and identifying ways to guarantee their stability are important [7]. In recent years, the investigation about the influence of light on the stability of drugs has gained more and more importance. Information about photo stability of drugs can help to determine the storage conditions in order to ensure the safety and quality of pharmaceutical products [8].

There are some studies reported for determination of darunavir in biological samples using high-performance liquid chromatography (HPLC) with ultraviolet detector or mass spectrometer [9-14] and two recent reported studies for determination of darunavir in tablets and darunavir raw material in a stress test $[15,16]$. It was not possible to see how resolved are the degradation products peaks that emerged during stress test and the peak for the drug in the published stress test. Moreover, buffer was applied as mobile phase which does not contribute to a longer life of chromatographic column. There is no monograph for darunavir raw material or product in any pharmacopeia or official compendium.

The aim of this work was to study the stability of darunavir raw material and tablets and to develop and validate a HPLC method to determine darunavir ethanolate raw material and tablets in the presence of degradation products. The novelty of this study is in understanding the factors that affect darunavir ethanolate stability in tablets, which is the first step to unravel the path of instability and know each degradation product. To evaluate all samples in this study, we have developed an accurate, simple and reliable stability-indicating HPLC method free of placebo interferences. The stability-indicating method was able to resolve the degradation product peaks and the peak of the drug, wherefore, it can be applied during degradation product monitoring studies.

\section{Material and Methods}

2.1. Chemicals. Darunavir chemical reference (assigned purity of 98\%) was obtained from Sequoia Research (Pangbourne, United Kingdom). Darunavir ethanolate tablets $300 \mathrm{mg}$ (Prezista) were purchased from local markers. The raw material was extracted from Prezista tablets by ethanol extraction using an adaptation of the method described by Berginc and coworkers [17]. The purity of extracted darunavir was confirmed by HPLC and by infrared spectroscopy analysis. The HPLC method used to confirm the purity and to standardize the raw material against the chemical reference was that described by Goldwirt and coworkers [14], whereupon the darunavir peak surface represented $96.6 \%$ of the total chromatogram surface area and it contains $94 \%$ of darunavir when analyzed against darunavir chemical reference. Darunavir raw material (extracted from tablets) and darunavir chemical reference were evaluated by infrared spectroscopy and they showed the same spectrum. The ethanolic extraction was applied because the placebo ingredients have poor solubility in ethanol, and the drug is soluble in this solvent. Furthermore to ensure the purity of the extracted raw material it was analyzed by HPLC method using the Goldwirt and coworkers method. The amount of mass remainder from the extraction of the darunavir from Prezista which was free of the active pharmaceutical ingredient was used as placebo.

Acetonitrile LC grade was purchased from JTBaker (Center Valley, USA) and Tedia (Fairfield, USA). Ultrapurified water $(<18<\mathrm{mu}>S)$ was prepared in-house by using DirectQR water system (Millipore Corporation, Billerica, USA). Prior to use, mobile phase solvents were degassed in an ultrasonic bath for $30 \mathrm{~min}$. Sodium hydroxide, hydrochloric acid, and hydrogen peroxide (reagent grade) were purchased from Merck (Darmstadt, Germany). Purified water was used to prepare the mobile phase, and the sample and the standard solutions were filtered through a $0.45 \mu \mathrm{m}$ membrane filter.

2.2. Apparatus. Liquid chromatography apparatus (Waters Corporation, Milford, MA, USA), equipped with a Waters 1525 binary pump, a Rheodyne Breeze $7725 \mathrm{i}$ manual injector, and a Waters 2487 UV-VIS wavelength detector, was used. In addition, a liquid chromatography apparatus Shimadzu R CLASS-VP, with PDA detector (Shimadzu Corporate, Japan), was employed. HPLC analysis was conducted by using a RP C18 column (Symmetry, $5 \mu \mathrm{m}, 250 \times 4.6 \mathrm{~mm}$, Waters). An infrared spectrometer equipment with Fourrier transformation (FTIR-Irprestige 21, Shimadzu Corporate, Japan) was used to analyze the raw material.

2.3. LC Conditions. Chromatographic analysis was performed in isocratic mode. Mobile phase consists of acetonitrile water $(50: 50, \mathrm{v} / \mathrm{v})$ at a flow rate of $1 \mathrm{~mL} / \mathrm{min}$. The injection volume was $20 \mu \mathrm{L}$ and the detection wavelength was $267 \mathrm{~nm}$. Total run time was $9 \mathrm{~min}$. All experiments were 
performed at room temperature $\left(25^{\circ} \mathrm{C}\right)$, and the total area of peak was used to quantify darunavir.

2.4. Standard and Sample Solutions Preparation. A stock standard solution of darunavir was prepared by dissolving $3.0 \mathrm{mg}$ of the raw material in $100 \mathrm{~mL}$ volumetric flask. To prepare the stock sample solution, twenty tablets were accurately weighed, finely pulverized and mixed using a mortar and pestle. An amount of tablet powder equivalent to $3.0 \mathrm{mg}$ of darunavir was weighed and transferred into a $100 \mathrm{~mL}$ volumetric flask. The drug was dissolved in $20 \mathrm{~mL}$ of methanol and $50 \mathrm{~mL}$ of water. It was sonicated for $10 \mathrm{~min}$, and then the volume was making up with water. Working solutions were prepared in triplicate by diluting the stock standard solution with water to reach six final concentrations: $6,9,12,15,18$, and $21 \mu \mathrm{g} / \mathrm{mL}$. The concentration used to assess the darunavir content is $15 \mu \mathrm{g} / \mathrm{mL}$. Placebo solution was prepared at the same form.

\subsection{Forced Degradation Studies/Specificity}

2.5.1. Acid, Alkali, Neutral, Oxidative, and Photo Degradation Studies. The procedure of degradation studies was conducted in agreement with ICH guide to stability studies [18]. Sample solutions were prepared at concentration of $15 \mu \mathrm{g} / \mathrm{mL}$ in water, $0.1 \mathrm{M} \mathrm{HCl}, 0.1 \mathrm{M} \mathrm{NaOH}$, and $\mathrm{H}_{2} \mathrm{O}_{2} 3 \%$; they were stored at room temperature for 30 minutes, and they were stored for 3,6 , and $12 \mathrm{~h}$ at $90^{\circ} \mathrm{C}$ in bath. After that, aliquots of these solutions were removed and evaluated by LC method. In addition, sample solutions were prepared in water with $20 \%$ of methanol and using the same concentration $(15 \mu \mathrm{g} / \mathrm{mL})$. These preparations were exposed to UVC radiation ( $254 \mathrm{~nm}$ ) for $1 \mathrm{~h}$. The stress degradation was carried out exposing the solutions in flasks. Control samples protected from light with aluminum foil were also placed in exposition concurrently in the light chamber. After that, aliquots of these solutions were removed and evaluated by LC method.

2.5.2. Specificity. The specificity of the method was determined by darunavir standard, raw material, tablets, and its placebo and by subjecting a sample solution to accelerated degradation by acid, basic, neutral, and oxidative conditions to evaluate the interference in the quantitation of darunavir. The method was validated in agreement with ICH guide to validation of methods [19].

2.6. Linearity and Precision. The calibration curve was obtained at six concentration levels: 6, 9, 12, 15, 18, and $21 \mu \mathrm{g} / \mathrm{mL}$ using working standard solutions. The linearity was evaluated by the least square regression method with triplicate determinations at each concentration level. The validity of the assay was verified by means of ANOVA.

The precision of the method was determined by repeatability (intraday) and intermediate precision (interday). For repeatability test, three curves were constructed with the established six concentration levels using standard solutions in the same day; for intermediate precision, three curves were constructed with four concentration levels $(6,12,15$,

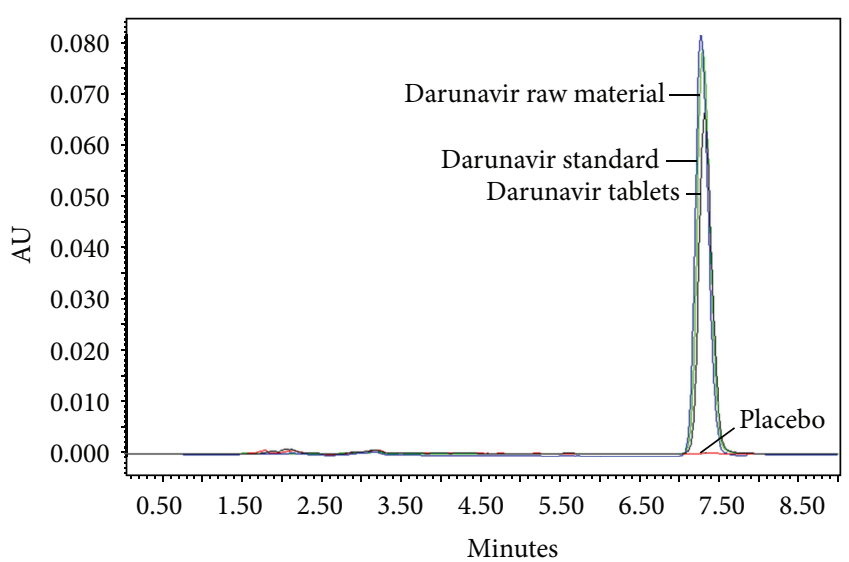

FIgURE 2: Overlay chromatograms for darunavir standard, raw material, tablets and its placebo at $15 \mathrm{~g} / \mathrm{mL}$ (room temperature $=$ $\left.20^{\circ} \mathrm{C}\right)$.

and $21 \mu \mathrm{g} / \mathrm{mL}$ ) using standard solutions in a different day. An interval of two days between repeatability and intermediate precision tests was observed. The results were expressed as percentage of relative standard deviation (RSD).

2.7. Accuracy. The accuracy of the method was assessed by recovery method. The recovery was determined by adding known amounts of darunavir raw material to placebo at the beginning of the process to obtain the six established concentration levels, in triplicate.

2.8. Detection and Quantitation Limits. The detection and quantitation were determined using calibration standards and they were calculated as 3 and $10 \sigma / S$, respectively, where $S$ is the slope of the calibration curve and $\sigma$ is the standard deviation of $y$-intercept of regression equation.

2.9. Robustness. Robustness was evaluated by Youden and Steiner method [20]. By this method seven different parameters could be evaluated by eight analytical runs employing factorial combination.

\section{Results and Discussion}

3.1. Analytical Development. Good separation and symmetry of darunavir peak were obtained by using Symmetry column and mix of acetonitrile and water $(50: 50, \mathrm{v} / \mathrm{v})$ as mobile phase. The LC method validated is fast, with retention time equal to $7.4 \mathrm{~min}$. The chromatograms of darunavir standard, raw material, tablets, and its placebo are shown in Figure 2.

The darunavir raw material used in this work was extracted from Prezista tablets by ethanol extraction. Its purity was tested by HPLC and by infrared spectroscopy. The infrared spectrum of darunavir standard and raw material are shown in Figure 3.

The most important chromatographic parameters monitored during the validation of the developed method are shown in Table 1 . The results from this monitoring can be 


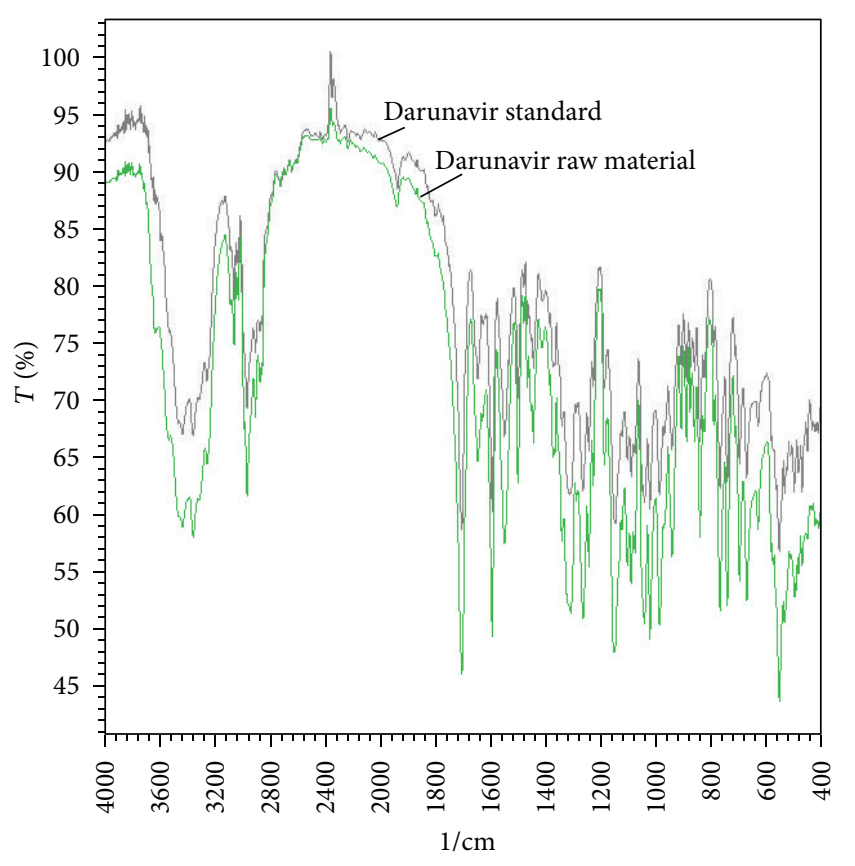

FIGURE 3: Overlay infrared spectrum of darunavir standard and extracted raw material.

compared with the acceptance criteria widely used in liquid chromatography.

3.2. Stability Study. The validated LC method was applied as an indicating stability method. It was able to separate the possible degradation products (Figure 4$)$. The stress conditions tested were aqueous, alkaline $(0.1 \mathrm{M} \mathrm{NaOH})$, acid $(0.1 \mathrm{M}$ $\mathrm{HCl})$, oxidative medium ( $\left.3 \% \mathrm{v} / \mathrm{v}_{2} \mathrm{O}_{2}\right)$, and light $(254 \mathrm{~nm})$ at ambient temperature and under heating $\left(90^{\circ} \mathrm{C}\right)$. Darunavir showed to be stable under UVC light and aqueous medium, but unstable under alkaline, acid, and oxidative conditions. In these conditions, some degradation products emerged. In the presence of alkaline and oxidative media darunavir was almost completely consumed over time. Figure 4 shows the chromatograms obtained from alkaline, acid, and oxidative stress where the main degradation product peaks were marked between the peaks from the blanks and the drug.

The stability-indicating method was able to separate completely the peaks related to degradation products and the drug and solve the main degradation product peaks wherefore, it can be applied not just to monitor the drug but to monitor the degradation products during stability studies as well.

Darunavir has a carbamate function in its structure. As it is known and discussed for Larson and Weber [21] and for Dittert and Higuchi [22], the carbamate can be easily hydrolyzed mainly in basic media.

In basic stress, probably, the carbamate function suffered hydrolysis, and this reaction is accelerated by the heating, as expected, because after 12 hours under heating the darunavir peak had disappeared and a degradation product peak had risen (Figure 4). In acid and oxidative medium, some probable degradation products emerged and all of them are
TABLE 1: Chromatographic parameters and the acceptance criteria for darunavir determination by developed LC method.

\begin{tabular}{lcc}
\hline Chromatographic parameters & Results & Acceptance criteria \\
\hline$t_{R}$ (retention time, min) & 7.4 & - \\
$T_{0}$ (column dead time, min) & 1.2 & - \\
$k^{\prime}$ (retention factor) & 5.16 & $2<k^{\prime}<10$ \\
$N$ (column efficiency) & 2433 & $N>2000$ \\
\hline
\end{tabular}

more polar than darunavir molecule since their peaks showed minor retention times in comparison with darunavir peak. The chemical structure of darunavir (Figure 1) has some sites where some reactions as hydroxylation may occur. All of these degradation products are under investigation in our lab.

Figures 3 and 4 show a small variation in retention time of the drug in the chromatograms. It occurs because of room temperature variation since the HPLC do not have column oven. However, this variation does not affect the analytical assay as shown by the robustness test.

3.3. Validation of the Method. The method was applied for the quality control of darunavir raw material and tablets and to quantify the drug in a stability stress test. The samples were analyzed using a PDA detector which shows no coelution in darunavir peak.

The validity of the method was verified by means of the ANOVA. According to ANOVA, there is a statistically significant linear regression in the tested concentration range from 6 to $21 \mu \mathrm{g} / \mathrm{mL}$ (Fcalculated $>/$ Fcritical; $P=0.05$ ). The equation of the curve is $y=43272.84 X+6875.41$, and the coefficient of correlation is 0.997 . The concentration levels applied in linearity test are considerately low which is very important for the study of stress as it enables detection of degradation products under these conditions.

The precision of the method was determined by repeatability (intraday) and intermediate precision (interday) and was expressed as RSD (\%) of a series of measurement. The result obtained shows RSD mean $1.75 \%$, indicating very good intra-day precision. Interday variability was calculated from assays on 3 days and shows a mean RSD of 3.28\% (Table 2). The accuracy of the method was determined by the mean recovery. The mean percentage recovery was $99.64 \%$ (Tables 2 and 3 ) indicating a very good agreement between the true value and the value found.

Robustness testing is useful in order to prove that typical variations to the method are negligible in the procedure outcome, being usually studied by deliberately changing critical parameters and monitoring possible alterations. A method is said to be robust when these alterations produce no significant changes in its results. The robustness test by Youden and Steiner method [20] can evaluate the interference of low and deliberated changes in seven parameters on the darunavir content. The parameters evaluated were chromatographic column $(\mathrm{A} / \mathrm{a})$, wavelength $(\mathrm{B} / \mathrm{b})$, flow rate $(\mathrm{C} / \mathrm{c})$, mobile phase $(\mathrm{D} / \mathrm{d})$, sonication time $(\mathrm{E} / \mathrm{e})$, room temperature $(\mathrm{F} / \mathrm{f})$, and acetonitrile brand (G/g). Table 4 shows the factorial combination of analytical parameters evaluated, and Table 5 


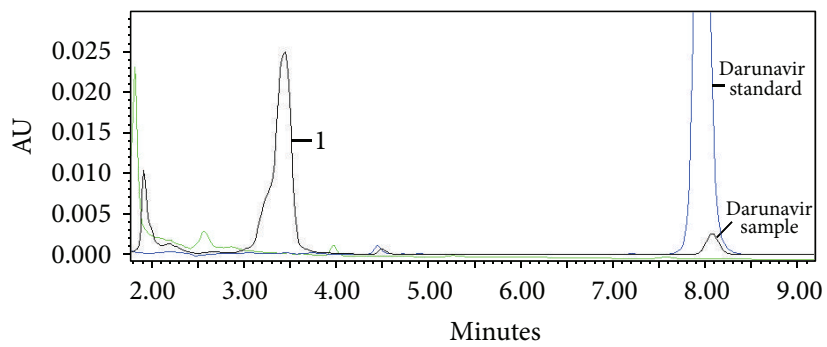

(a)

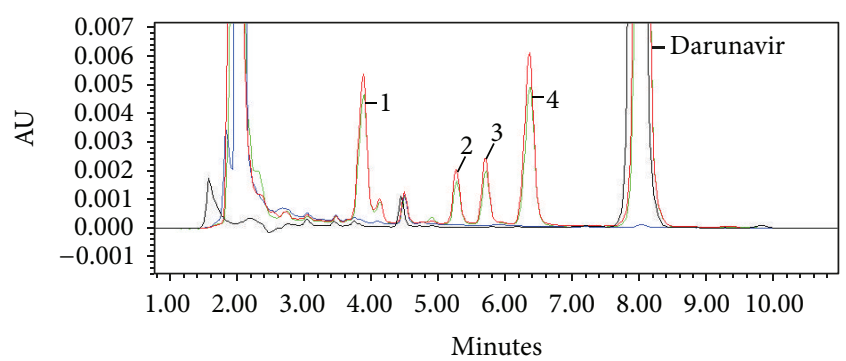

(b)

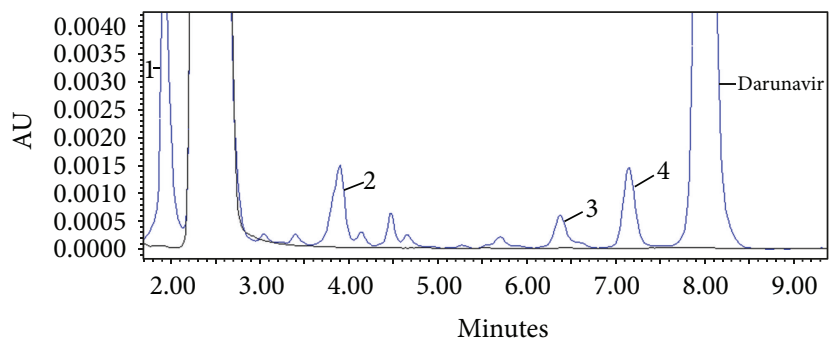

(c)

FIGURE 4: Overlay chromatograms obtained from alkaline (a), acid (b), and oxidative (c) stress darunavir tablets, its placebo, and the blank of the media heated for 6 hours. The possible degradation products are shown, and they were highlighted with numbers.

TABLE 2: Validation parameters for chromatographic method.

\begin{tabular}{|c|c|}
\hline Parameters & Chromatographic method \\
\hline Useful concentration, $\mu \mathrm{g} / \mathrm{mL}$ & 15 \\
\hline Analytical curve & $43272.84 X+6875.41$ \\
\hline Determination coefficient $\left(r^{2}\right)$ & 0.997 \\
\hline RSD of repeatability $^{\mathrm{a}}(\%, n=18)$ & 1.75 \\
\hline RSD intermediate precision $(\%, n=12)$ & 3.28 \\
\hline Accuracy (\%) & 99.64 \\
\hline $\operatorname{RSD}$ of $\operatorname{accuracy}^{\mathrm{a}}(\%, n=18)$ & 1.36 \\
\hline Detection limit ${ }^{\mathrm{b}}, \mu \mathrm{g} / \mathrm{mL}$ & 0.87 \\
\hline Quantitation limit ${ }^{\mathrm{c}}, \mu \mathrm{g} / \mathrm{mL}$ & 2.89 \\
\hline
\end{tabular}

${ }^{\mathrm{a}}$ Measured at the six concentration levels; ${ }^{\mathrm{b}} 3 \sigma / S ;{ }^{\mathrm{c}} 10 \sigma / S$.

TABLE 3: Recovery data of standard solutions added to the placebo analyzed by the proposed chromatographic method.

\begin{tabular}{lcc}
\hline Method & $\begin{array}{c}\text { Added amount } \\
(\mu \mathrm{g} / \mathrm{mL})\end{array}$ & Recovery $^{\mathrm{a}}(\%) \pm \mathrm{RSD}$ \\
\hline 6.0 & $101.5 \pm 0.5$ \\
& 9.0 & $99.9 \pm 1.0$ \\
Chromatographic & 12.0 & $98.5 \pm 0.6$ \\
method & 15.0 & $98.8 \pm 1.2$ \\
& 18.0 & $98.9 \pm 0.7$ \\
& 21.0 & $98.9 \pm 1.0$ \\
\hline
\end{tabular}

aean of three replicates.

shows the analytical parameters and variations. The analytical parameters were varied relative to standard conditions.
TABLE 4: Factorial combination of Youden and Steiner [20] test.

\begin{tabular}{lcccccccc}
\hline \multirow{2}{*}{ Parameter } & \multicolumn{7}{c}{ Factorial combination } \\
& 1 & 2 & 3 & 4 & 5 & 6 & 7 & 8 \\
\hline A, a & A & A & A & A & a & a & a & a \\
B, b & B & B & b & b & B & B & B & b \\
C, c & C & c & C & c & C & C & C & c \\
D, d & D & D & d & d & D & D & D & D \\
E, e & E & e & E & e & E & E & E & E \\
F, f & F & f & f & F & F & F & F & F \\
G, g & G & g & g & G & G & G & G & g \\
Results & S & $t$ & $u$ & $v$ & $x$ & $y$ & $W$ & $z$ \\
\hline
\end{tabular}

To evaluate the effect of each variation on the darunavir assay, the following equation was used [23]:

$$
\begin{aligned}
\mathrm{A}, \mathrm{a}= & \frac{x+y+w+z}{4} \\
& -\frac{s+t+u+v}{4}(\text { equation to parameter } \mathrm{A}, \mathrm{a}) .
\end{aligned}
$$

The major effect on the darunavir content was shown when the parameter sonication time was modified. The values obtained by the above equation were E, e (1.26\%) and E, $\mathrm{e}^{\prime}$ $(1.50 \%)$. Therefore, sonication time should be obeyed rigorously. The results to other parameters variation show values considerably low and not significant in routine analyses. 
TABLE 5: Analytical parameters and their variations.

\begin{tabular}{|c|c|c|}
\hline & Parameters & Variations \\
\hline A & $\begin{array}{l}\text { Chromatographic } \\
\text { column }\end{array}$ & $\begin{array}{c}\text { A: Waters Symmetry } \\
\text { a: } \text { Agilent }^{\mathrm{a}}\end{array}$ \\
\hline B & Wavelength & $\begin{array}{l}\text { B: } 267 \mathrm{~nm} \\
\text { b: } 268 \mathrm{~nm} \\
\mathrm{~b}^{\prime}: 266 \mathrm{~nm}\end{array}$ \\
\hline $\mathrm{C}$ & Flow rate & $\begin{array}{l}\mathrm{C}: 1.0 \mathrm{~mL} / \mathrm{min} \\
\text { c: } 1.1 \mathrm{~mL} / \mathrm{min} \\
c^{\prime}: 0.9 \mathrm{~mL} / \mathrm{min}\end{array}$ \\
\hline $\mathrm{D}$ & Mobile phase & $\begin{array}{l}\text { D: } 50: 50^{\mathrm{b}} \\
\mathrm{d}: 55: 45^{\mathrm{b}} \\
\mathrm{d}^{\prime}: 45: 55^{\mathrm{b}}\end{array}$ \\
\hline $\mathrm{E}$ & Sonication time & $\begin{array}{l}\text { E: } 10 \mathrm{~min} \\
\mathrm{e}: 11 \mathrm{~min} \\
\mathrm{e}^{\prime}: 9 \mathrm{~min}\end{array}$ \\
\hline $\mathrm{F}$ & Room temperature & $\begin{array}{l}\mathrm{F}: 25^{\circ} \mathrm{C} \\
\mathrm{f}: 20^{\circ} \mathrm{C}\end{array}$ \\
\hline G & Acetonitrile brand & $\begin{array}{l}\text { G: JTBaker } \\
\text { g: Tedia }\end{array}$ \\
\hline
\end{tabular}

\section{Conclusion}

The proposed method was used successfully to determine darunavir raw material and tablets even in presence of degradation products. The results of the validation studies show that the LC method is accurate; it has significant linearity and precision without any interference from the excipient. The stability tests results showed that darunavir is significantly instable. In acid, alkaline, and oxidative media under heating, new substances were produced. In basic media, probably, darunavir molecule has its carbamate completely hydrolyzed. The stability-indicating method was able to separate completely the peaks related to degradation products and the drug and solve the main degradation product peaks; wherefore, this stability-indicating method can be used to monitor the degradation products in low concentrations in which there is linearity. The degradation products formed under basic, acid and oxidative medium are now under investigation in order to unravel its molecule and the pathway of darunavir degradation.

\section{Conflict of Interests}

The authors do not have any direct financial relation with the commercial identities mentioned in this paper. There is no conflict of interests for any of the authors.

\section{Acknowledgments}

The authors thank PADC-UNESP, FUNDUNESP, CNPq, and FAPESP for the financial support. In addition, the authors would like to thank to Cássia Regina Primila Cardoso PhD., and the phytochemical laboratory of the Institute of Chemistry of Araraquara/UNESP, Brasil, for the use of the liquid chromatography with PDA detector.

\section{References}

[1] World Health Organization, AIDS Epidemic Update, November 2012, http://www.who.int/mediacentre/news/releases/ 2009/hiv_aids_20091124/en/index.html.

[2] P. Sharma and S. Garg, "Pure drug and polymer based nanotechnologies for the improved solubility, stability, bioavailability and targeting of anti-HIV drugs," Advanced Drug Delivery Reviews, vol. 62, no. 4-5, pp. 491-502, 2010.

[3] A. K. Ghosh, J. F. Kincaid, W. Cho et al., "Potent HIV protease inhibitors incorporating high-affinity P2-ligands and (R)-(hydroxyethylamino)sulfonamide isostere," Bioorganic and Medicinal Chemistry Letters, vol. 8, no. 6, pp. 687-690, 1998.

[4] D. Back, V. Sekar, and R. M. W. Hoetelmans, "Darunavir: pharmacokinetics and drug interactions," Antiviral Therapy, vol. 13, no. 1, pp. 1-13, 2008.

[5] J. C. R. Corrêa, D. M. D’Arcy, C. H. R. Serra, and H. R. N. Salgado, "Darunavir: a critical review of its properties, use and drug interactions," Pharmacology, vol. 90, no. 1-2, pp. 102-109, 2012.

[6] Food and Drug Administration, "New labeling approved for Prezista (darunavir)," November 2012, http://www.fda.gov/ForConsumers/ByAudience/ ForPatientAdvocates/HIVandAIDSActivities/ucm236771.htm.

[7] J. C. R. Corrêa, C. Reichman, C. D. Vianna-Soares, and H. R. N. Salgado, "Stability study of fluconazole applying validated bioassay and stability-indicating LC methods," Journal of Analytical \& Bioanalytical Techniques, vol. 2, p. 126, 2011.

[8] P. Kovaríkova, M. Mokry, and J. Klimes, "Photochemical stability of nimesulide," Journal of Pharmaceutical and Biomedical Analysis, vol. 31, no. 4, pp. 827-832, 2003.

[9] A. Curran, M. Gutirerrez, E. Deig et al., "Efficacy, safety and pharmacokinetics of 900/100 mg of darunavir/ritonavir once daily in treatment-experienced patients," Journal of Antimicrobial Chemotherapy, vol. 65, no. 10, pp. 2195-2203, 2010.

[10] A. D’Avolio, M. Simiele, M. Siccardi et al., "A HPLC-MS method for the simultaneous quantification of fourteen antiretroviral agents in peripheral blood mononuclear cell of HIV infected patients optimized using medium corpuscular volume evaluation," Journal of Pharmaceutical and Biomedical Analysis, vol. 54, no. 4, pp. 779-788, 2011.

[11] A. D’Avolio, M. Simiele, M. Siccardi et al., "HPLC-MS method for the quantification of nine anti-HIV drugs from dry plasma spot on glass filter and their long term stability in different conditions," Journal of Pharmaceutical and Biomedical Analysis, vol. 52, no. 5, pp. 774-780, 2010.

[12] L. Else, V. Watson, J. Tjia et al., "Validation of a rapid and sensitive high-performance liquid chromatography-tandem mass spectrometry (HPLC-MS/MS) assay for the simultaneous determination of existing and new antiretroviral compounds," Journal of Chromatography B, vol. 878, no. 19, pp. 1455-1465, 2010.

[13] S. P. García, D. G. Tunica, and M. B. Serra, "Desarrollo y validación de un método para la determinación de darunavir en plasma mediante LC-MS/MS," Revista del Laboratorio Clínico, vol. 4, pp. 127-133, 2011. 
[14] L. Goldwirt, S. Chhun, E. Rey et al., "Quantification of darunavir (TMC114) in human plasma by high-performance liquid chromatography with ultra-violet detection," Journal of Chromatography $B$, vol. 857, no. 2, pp. 327-331, 2007.

[15] L. Satyanarayana, S. V. Naidu, N. M. Rao, A. Kumar, and K. Suresh, "The estimation of darunavir in tablet dosage form by RP-HPLC," Asian Journal of Research in Pharmaceutical Sciences, vol. 1, pp. 74-76, 2011.

[16] B. V. R. Reddy, G. Jyothi, B. S. Reddy, N. V. V. S. Raman, K. S. C. Reddy, and C. Rambabu, "Stability-Indicating HPLC method for the determination of darunavir ethanolate," Journal of Chromatographic Science, vol. 51, no. 5, pp. 471-476, 2013.

[17] K. Berginc, T. Trdan, J. Trontelj, and A. Kristl, "HIV protease inhibitors: garlic supplements and first-pass intestinal metabolism impact on the therapeutic efficacy," Biopharmaceutics and Drug Disposition, vol. 31, no. 8-9, pp. 495-505, 2010.

[18] ICH, Validation of Analytical Procedures: Text and Methodology, Harmonized Tripartite Guideline Q1A (R2), 2003.

[19] ICH, Validation of Analytical Procedures: Text and Methodology, Harmonized Tripartite Guideline Q2 (R1), 2005.

[20] W. J. Youden and E. H. Steiner, Statistical Manual of AOAC, Association of Official Analytical Chemistry. AOAC, Washington, DC, USA, 1975.

[21] A. R. Larson and E. J. Weber, "Hydrolyses," in Reaction Mechanisms in Environmental Organic Chemistry, A. R. Larson and E. J. Weber, Eds., pp. 103-167, CRC Press, Boca Raton, Fla, USA, 1994.

[22] L. W. Dittert and T. Higuchi, "Rates of hydrolysis of carbamate and carbonate esters in alkaline solution," Journal of Pharmaceutical Sciences, vol. 52, pp. 852-857, 1963.

[23] I. D. C. César and G. A. Pianetti, "Robustness evaluation of the chromatographic method for the quantitation of lumefantrine using Youden's test," Brazilian Journal of Pharmaceutical Sciences, vol. 45, no. 2, pp. 235-240, 2009. 

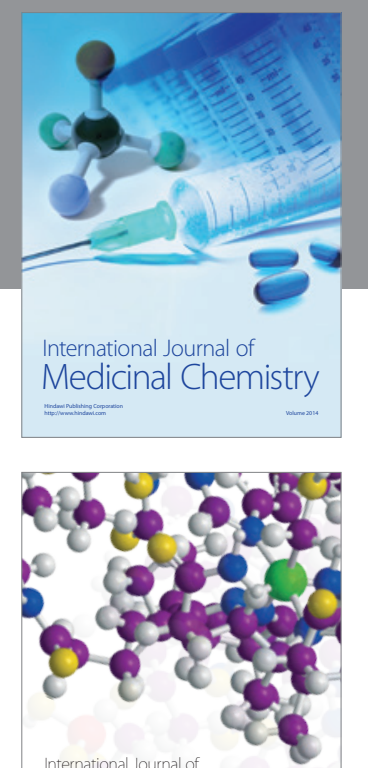

\section{Carbohydrate} Chemistry

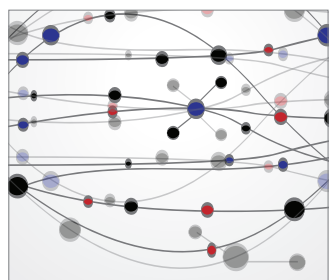

The Scientific World Journal
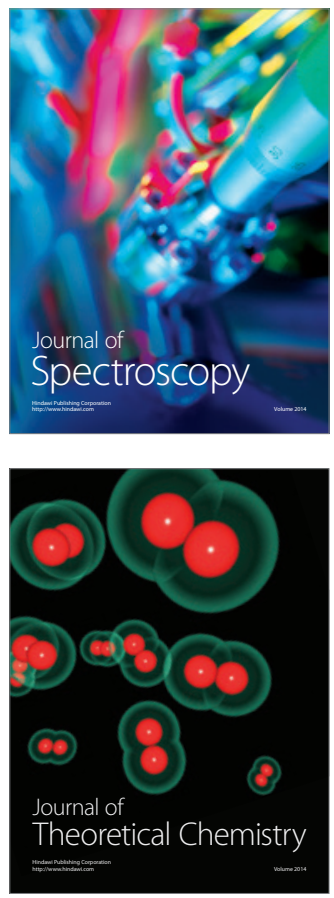
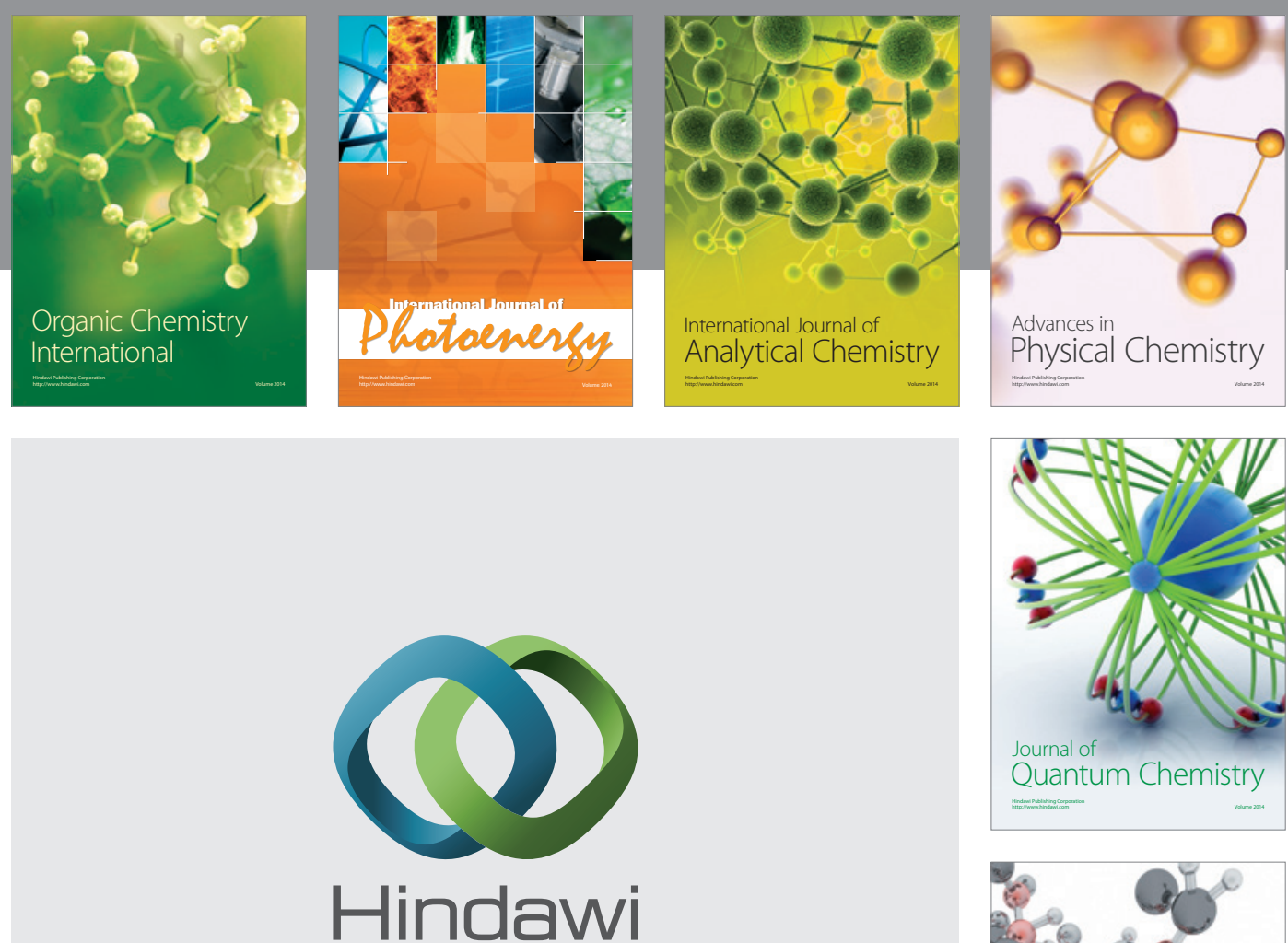

Submit your manuscripts at

http://www.hindawi.com

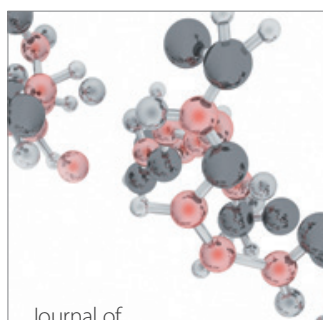

Analytical Methods

in Chemistry

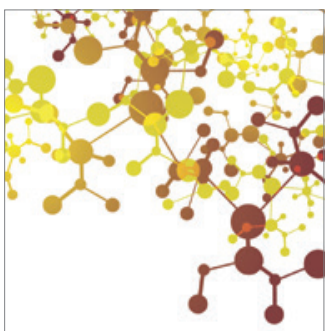

Journal of

Applied Chemistry

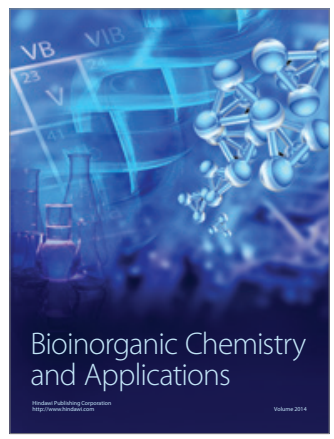

Inorganic Chemistry
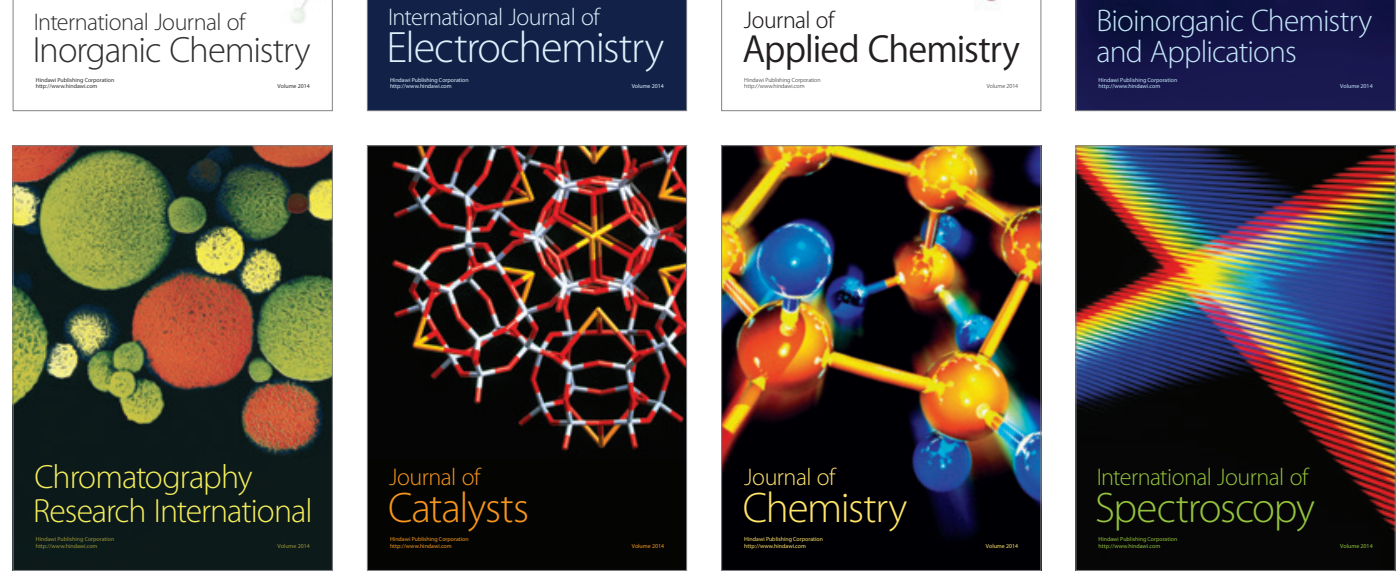